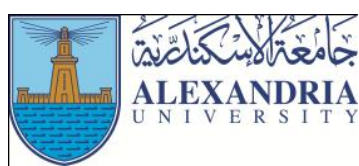

\author{
Journal of Applied Sports Science \\ April 2017, Volume 7, No. 1 \\ www.jass.alexu.edu.eg
}

\title{
Effect of Competition Anxiety on Sleep Disorders within Football Players
}

\author{
Mohamed Mounir Abd el Razek ${ }^{1}$ \\ ${ }^{1}$ Assistant Professor, Sport Psychology Department, Faculty of Physical Education, Damietta University, Egypt
}

\begin{abstract}
This research aims at developing sleep disorders scale for football players, investigate the relationship between competition anxiety aspects and sleep disorders aspects within football players in Damietta Governorate. Also, investigate differences in competition anxiety aspects and sleep disorders aspects within football players in Damietta Governorate, identify effect size of competition anxiety on sleep disorders anxiety for football players in Damietta Governorate, and identify differences in competition anxiety aspects and sleep disorders aspects within football players in Damietta Governorate according to competition level (Premier League B - third class). Two hundred subjects randomly recruited from football players in Damietta governorate. Sixty football players (from Damietta club (Premier League B) and Damietta yarn (third class) participated in main study. Sport competition anxiety test and sleep disorder scale used as data collecting tools. The most important results indicated that two there is a statistically significant correlation between competition anxiety aspects and some sleep disorders aspects within football players.
\end{abstract}

\section{Introduction}

$\mathrm{P}$ sychological stresses by coach on players or by team members on other team members are of things that cause anxiety, tension, high excitement, and create an unhealthy environment among players.

Rateb (2007) argues that anxiety is of most important emotions, and is of most important psychological phenomena that affect athlete's performance and this effect may be positive and push them to do more, or negative hamper performance (p. 157).

Sleep is body vital activity and a basic irreplaceable type of comfort maintains health and has a great effect on athlete functionality and achievement.

Sometimes there may be a disturbance in sleep quality before competition. This relates to excessive anxiety before competition start. Therefore, mental training and careful follow-up of health rules in these cases often help to eliminate anxiety and disturbance. (Fullagar et al., 2014)

Football players' life and living circumstances might affected by anxiety state resulting from sports competition. This research is important as a try to overcome negative effects of competitions to help players to focus their attention on positive thoughts and exclude negative ones to improve their performance, where it noted that studies conducted in this area did not address the effect of competition anxiety on sleep disorders within football players.

This research aims at developing sleep disorders scale for football players, investigate the relationship between competition anxiety aspects and sleep disorders aspects within football players in Damietta Governorate. Also, investigate differences in competition anxiety aspects and sleep disorders aspects within football players in Damietta Governorate, identify effect size of competition anxiety on sleep disorders anxiety for football players in Damietta Governorate, and identify differences in competition anxiety aspects and sleep disorders aspects within football players in Damietta Governorate according to competition level (Premier League B - third class).

Researcher hypothesized the following

1- The proposed scale measures sleep disorders within football players in Damietta Governorate. 
2- There is statistically significant correlation between competition anxiety aspects and sleep disorders aspects within football players in Damietta Governorate.

3- There are statistical significant differences between first measurement (one month before competition) and second measurement (one hour before competition) in competition anxiety aspects and sleep disorders aspects within football players in Damietta.

4- Competition anxiety effect size on sleep disorders anxiety is $\geq 0.14$ within football players in Damietta Governorate

5- There are statistical significant differences competition anxiety aspects and sleep disorders aspects within football players in Damietta Governorate according to competition level (Premier League B third class).

\section{Method}

\section{Subjects:}

Two hundred subjects randomly recruited from football players in Damietta governorate. Sixty football players (from Premier League B and third class) participated in main study, 140 football players (from Premier League $\mathrm{B}$, third class, and fourth class used to check scales validity and reliability.

\section{Measures}

1- Sport completion anxiety test (prepared by Rainer Martens) , Arabized by Rateb (2007) , consists of 27 phrases distributed on 3 aspects (Cognitive anxiety state, somatic anxiety state, and self-trust state(p. 181)

2- Sleep disorders scale consists of 20 phrases (four phrases/aspect), the five aspects are sleep sufficiency, usual sleep efficiency, sleep effects, insomnia - sleep starting).

\section{Procedures}

\section{Developing sleep disorders scale for football players:}

Sleep disorders scale initial form prepared consists of (53) phrases administered to pilot sample (140 football players) to check scale validity and reliability

\section{Scale factorial validity}

To arrive to the simple structure of the sleep disorders scale for football players, factor analysis done using Hotelling's principal components method and orthogonal Varimax rotation. Factor accepted using Kaiser criteria (eigenvalue greater than one and absolute factor loadings > 0.30 (Hassan, 2011, p .447). Five factors accepted explained (64.31) of the variance.

The highest four loaded phrases for each factor retained, so the scale final form consists of (20) phrases (four phrases/factor). Highest phrases loaded on first factor are $(23,30,50,6)$ respectively, all related to "sleep sufficiency", which is the name given to this factor. Highest phrases loaded on second factor are $(1,4,16$, 22 ) respectively, all related to "usual sleep efficiency", which is the name given to this factor. Highest phrases loaded on third factor are $(1,4,16,22)$ respectively, all related to "usual sleep efficiency", which is the name given to this factor. Highest phrases loaded on fourth factor are $(52,35,40,33)$ respectively, all related to sleep effects on physical and psychological sides, so this factor named "sleep effects". Highest phrases loaded on fifth factor are $(12,13,14,3)$ respectively, all related to "sleep starting", which is the name given to this factor.

All correlation coefficients between factors were insignificant. According to Hassan (2011), if the correlation between factors is (0.59) and less, the correlation is insignificant, and positive correlations indicate that correlation between factors is acute, negative correlations indicate that the angle between factors is Obtuse. (p. 449)

\section{Main Study:}

First measurement conducted in the period (8$9) / 10 / 2016$, and second measurement in the period (812)/11/2016.

\section{Results and Discussion}

Sleep disorder scale for football players prepared where factorial validity resulted in five factors, with 20 phrases (all negative phrases in scale direction). Reliability splithalf coefficient $=0.95$, Cronbach Alpha coefficient $=$ 0.89, and test/retest coefficient $=0.90$. Comparative validity coefficient $=6.7$. All reliability and validity coefficients are statistically significant. Therefore, first hypothesis accepted. 
Table (1)

Correlation coefficients between competition anxiety and sleep disorders aspects within football players in Damietta Governorate $(n=60)$

\begin{tabular}{|c|c|c|c|c|c|c|}
\hline anxiety $\quad$ Sleep & $\begin{array}{c}\text { sleep } \\
\text { sufficiency }\end{array}$ & $\begin{array}{l}\text { usual sleep } \\
\text { efficiency }\end{array}$ & $\begin{array}{l}\text { sleep } \\
\text { effects }\end{array}$ & insomnia & sleep starting & $\begin{array}{l}\text { Sleep disorder } \\
\text { scale }\end{array}$ \\
\hline Cognitive anxiety & $0.52 *$ & $0.28 *$ & 0.16 & 0.19 & $0.36^{*}$ & $0.28^{*}$ \\
\hline somatic anxiety & $0.55^{*}$ & $0.31 *$ & 0.19 & $0.39^{*}$ & 0.06 & $0.47^{*}$ \\
\hline Self-trust & $-0.63^{*}$ & $-0.37 *$ & -0.02 & -0.12 & -0.24 & $-0.53 *$ \\
\hline
\end{tabular}

* Significant at $0.05(\mathrm{R}$ significant $=0.254)$

Table (1) results reveal statistically significant negative correlation between competition anxiety aspects (cognitive, somatic and self-trust) and (1) (sleep sufficiency and usual sleep efficiency) aspects in sleep disorders scale (2) total sleep disorder scale. The largest correlation were in self-trust, which negatively related with sleep sufficiency, usual sleep efficiency and total disorder scale. While cognitive and somatic anxiety aspects positively correlated with sleep sufficiency, usual sleep efficiency and total disorder scale. This indicates that the higher the self-trust within football players the higher sleep sufficiency and usual sleep efficiency, and the lower sleep disorders. In addition, the higher somatic and cognitive anxiety the lower sleep sufficiency and usual sleep efficiency, and the higher sleep disorders. This is due to sleep disorder phrases nature (all negative) while self-trust phrases are positive. This also attributed to that players who have high self-trust have the ability to control the environment to achieve goals. High level of self-trust leads to high performance and low emotional arousal because athlete believes in his ability to succeed and excel. Ibrahim (2008) results indicated that players who do not have self-trust are not able to deal with competitive situations (p.121). Rateb (2000) mentions that self-trust linked to athlete's self-esteem and that it is of most important psychological skills that athletes should have and must consider it when preparing them for competition. (p. 300)

Table (1) results also reveal statistically significant positive correlation between somatic anxiety aspect and insomnia aspect. This may attributed to that somatic anxiety usually accompanied by psychological and psychological disorders, which may cause insomnia and sleep instability. Ibrahim (2008) study results indicated that player's self-evaluation of competition status as a threat leads to psychological disorders, which in turn cause physiological changes, causing heart rate increase and raise systolic and diastolic blood pressure (p.131). Rateb (2000) argues that sports competition characterized by a kind of psychological stress causing some physical symptoms such as high blood pressure, increase number of breathing times, and Stomach disturbance (p.193)

Table (1) results also reveal statistically significant positive correlation between cognitive anxiety and sleep starting aspects. This may attributed to cognitive anxiety state usually accompany player entrance actual competition environment, his thinking about opposing team strengths and weaknesses and how to face this team. As well as waiting game start and what situations might be faced in it and how to deal with. The matter, which may cause cognitive anxiety increase and inability to start sleep. Rateb (2007) mentions that within distinctive features of Cognitive anxiety is the increase of undesired negative thoughts experienced by athlete, which usually leads to poor concentration and attention(p.196). Juliff, Halson \& Peiffer (2015) study results, which indicated $(83.5 \%)$ of athletes confirmed that one of the main reasons responsible for lack of sleep was ideas about competition, (43.8\%) stated because of nervousness. Ibrahim (2008) study results indicated that player's high intensity of cognitive anxiety, may be due to overload pressure by coach, which makes player thinks continuously on the game, which negatively affects him (p.156).

Table (1) results also reveal statistically insignificant correlation between competition anxiety aspects (cognitive, somatic and self-trust) and sleep effects aspect. This may be due weak effect of cognitive anxiety aspect on player's physical and physiological condition resulting from sleep. American Academy of Sleep Medicine (AASM) (2010) findings indicated that extended sleep time helped football players to improve athletic performance, reduce fatigue and increase strength.

Table (1) results also reveal statistically insignificant correlation between competition anxiety aspects (cognitive, and self-trust) and insomnia aspect. This 
may attributed to their weak effect on insomnia because of their physiological relation to physical anxiety. This is consistent with other results in this study; they also may be reasons for absence of insomnia.

Table (1) results also reveal statistically insignificant correlation between competition anxiety aspects (cognitive, and self-trust) and sleep starting aspect. This may attributed to their weak effect on sleep starting, as physical relaxation and self-trust due to good preparation for competition are of factors help to start sleep. This is in consistent with Arcos-Carmona et al (2011) study results, which stated that physical exercises and relaxation helped to improve sleep quality, reduce anxiety, and reduce psychological stresses. Thus, second hypothesis partially accepted.

Table (2)

Differences significance in sport anxiety and sleep disorders aspects between first and second measurement for football players in Damietta Governorate $(n=60)$

\begin{tabular}{|c|c|c|c|c|c|c|c|c|}
\hline \multirow[t]{2}{*}{ S.No. } & \multirow{2}{*}{ variables } & \multicolumn{2}{|c|}{$\begin{array}{c}\text { First measurement (1 } \\
\text { month before } \\
\text { competition) }\end{array}$} & \multicolumn{2}{|c|}{$\begin{array}{c}\text { Second measurement } \\
\text { (1 hour before } \\
\text { competition) }\end{array}$} & \multirow[t]{2}{*}{$\begin{array}{c}\text { Mean } \\
\text { differences }\end{array}$} & \multirow[t]{2}{*}{$\mathbf{T}$} & \multirow[t]{2}{*}{$\begin{array}{c}\text { Difference } \\
\%\end{array}$} \\
\hline & & Mean & SD & Mean & SD & & & \\
\hline 1 & Cognitive anxiety & 18.81 & 1.89 & 26.58 & 2.84 & -7.78 & $-12.73^{*}$ & $29.27 \%$ \\
\hline 2 & somatic anxiety & 13.27 & 1.79 & 18.19 & 2.57 & -4.91 & $-8.70^{*}$ & $26.99 \%$ \\
\hline 3 & Self-trust & 29.72 & 1.52 & 33.25 & 1.19 & -3.53 & $-9.56^{*}$ & $10.61 \%$ \\
\hline 4 & sleep sufficiency & 7.42 & 1.6 & 11.77 & 0.43 & -4.35 & $-12.42 *$ & $36.96 \%$ \\
\hline 5 & usual sleep efficiency & 6.88 & 1.49 & 10.65 & 0.75 & -3.77 & $-11.79 *$ & $35.39 \%$ \\
\hline 6 & sleep effects & 7.34 & 1.36 & 10.29 & 0.46 & -2.94 & $-10.91 *$ & $28.57 \%$ \\
\hline 7 & insomnia & 7.5 & 0.69 & 9.79 & 0.41 & -2.29 & $-14.46^{*}$ & $23.39 \%$ \\
\hline 8 & sleep starting & 7.42 & 0.50 & 9.33 & 0.48 & -1.91 & $-14.49 *$ & $20.47 \%$ \\
\hline 9 & Sleep disorder scale & 36.56 & 1.48 & 51.83 & 3.63 & -15.27 & $-12.86^{*}$ & $29.46 \%$ \\
\hline
\end{tabular}

* Significant at $0.05(\mathrm{~T}$ significant $\mathbf{= 2 . 0 0})$

Table (2) results reveal statistically significant differences between first and second measurements of competition anxiety aspects (cognitive, somatic and self-trust) towards second measurement. Largest differences was in cognitive anxiety. This may attributed to the fact that as competition is close, as more the football player's emotional state, which characterized by feeling tension and excitement as result of fear and danger anticipation from next competitive situation. This emotional state's situation varies from situation to another depending player's estimation of threat intensity and type. This may be part of player's readiness to compete, depending on the importance of the competitive situation for the player. Ibrahim (2008) study results stated that players' cognitive anxiety increases one hour before competition, which in turn increased their inability to concentrate". (p.131). Rateb (2000) argues that many players have physical skills qualify for successful performance but suffer from low self-trust in their abilities, especially before competition. (p.203)

Table (2) results reveal statistically significant differences between first and second measurements of competition in sleep disorder aspects (sleep sufficiency, usual sleep efficiency, sleep effects, insomnia, and sleep starting) and in sleep disorder scale total. Largest differences was in sleep sufficiency. This may attributed to that sports competition and the associated stress may negatively affect players in their daily lives. Salama (2001) assure that attention should be given to athletes' psychological preparation as one of important factors on which player's self-trust is built, which makes player ready to participate in competition with appropriate anxiety level enables to fight until win (p.147)

Thus, third hypothesis accepted 
Table (3)

Effect size of cognitive anxiety aspects (cognitive, somatic, and self-trust) on sleep disorder aspects for football players in Damietta Governorate $(n=60)$

\begin{tabular}{|c|c|c|c|c|c|c|c|}
\hline Independent variable & $\begin{array}{c}\text { Dependent } \\
\text { variables }\end{array}$ & Variance source & $\begin{array}{l}\text { Sum of } \\
\text { squares }\end{array}$ & DF & $\begin{array}{c}\text { Mean } \\
\text { squares }\end{array}$ & $\mathbf{F}$ & $\begin{array}{c}\text { Eta } \\
\text { squared }\end{array}$ \\
\hline \multirow{18}{*}{ Cognitive anxiety } & \multirow{3}{*}{$\begin{array}{c}\text { sleep } \\
\text { sufficiency }\end{array}$} & Between group & 890.58 & 2 & 148.43 & 26.94 & 0.74 \\
\hline & & within groups & 290.00 & 57 & 5.5 & & \\
\hline & & Total & 1182.58 & 59 & & & \\
\hline & \multirow{3}{*}{$\begin{array}{c}\text { usual } \\
\text { sleep } \\
\text { efficiency }\end{array}$} & Between group & 644.28 & 2 & 92.04 & 8.89 & 0.53 \\
\hline & & within groups & 538.29 & 57 & 10.35 & & \\
\hline & & Total & 1182.58 & 59 & & & \\
\hline & \multirow{3}{*}{$\begin{array}{c}\text { sleep } \\
\text { effects }\end{array}$} & Between group & 890.58 & 2 & 14.43 & 2.94 & 0.12 \\
\hline & & within groups & 292.00 & 57 & 9.5 & & \\
\hline & & Total & 1182.58 & 59 & & & \\
\hline & \multirow{3}{*}{ insomnia } & Between group & 275.19 & 2 & 18.79 & 1.17 & 0.06 \\
\hline & & within groups & 907.39 & 57 & 16.49 & & \\
\hline & & Total & 1182.58 & 59 & & & \\
\hline & \multirow{3}{*}{$\begin{array}{c}\text { sleep } \\
\text { starting }\end{array}$} & Between group & 311.16 & 2 & 103.72 & 6.66 & 0.26 \\
\hline & & within groups & 871.41 & 57 & 15.56 & & \\
\hline & & Total & 1182.58 & 59 & & & \\
\hline & \multirow{3}{*}{$\begin{array}{c}\text { Sleep } \\
\text { disorder } \\
\text { scale }\end{array}$} & Between group & 599.25 & 2 & 85.6 & 7.63 & 0.51 \\
\hline & & within groups & 583.33 & 57 & 11.21 & & \\
\hline & & Total & 1182.58 & 59 & & & \\
\hline \multirow{18}{*}{ Somatic anxiety } & \multirow{3}{*}{$\begin{array}{c}\text { sleep } \\
\text { sufficiency }\end{array}$} & Between group & 475.09 & 2 & 79.18 & 26.58 & 0.75 \\
\hline & & within groups & 157.88 & 57 & 2.97 & & \\
\hline & & Total & 632.98 & 59 & & & \\
\hline & \multirow{3}{*}{$\begin{array}{c}\text { usual } \\
\text { sleep } \\
\text { efficiency }\end{array}$} & Between group & 360.51 & 2 & 51.5 & 9.82 & 0.54 \\
\hline & & within groups & 272.46 & 57 & 6.24 & & \\
\hline & & Total & 632.98 & 59 & & & \\
\hline & \multirow{3}{*}{$\begin{array}{l}\text { sleep } \\
\text { effects }\end{array}$} & Between group & 357.98 & 2 & 59.66 & 1.49 & 0.06 \\
\hline & & within groups & 275.00 & 57 & 57.18 & & \\
\hline & & Total & 632.98 & 59 & & & \\
\hline & \multirow{3}{*}{ insomnia } & Between group & 340.58 & 2 & 85.14 & 16.01 & 0.57 \\
\hline & & within groups & 292.4 & 57 & 5.31 & & \\
\hline & & Total & 632.98 & 59 & & & \\
\hline & \multirow{3}{*}{$\begin{array}{c}\text { sleep } \\
\text { starting }\end{array}$} & Between group & 41.67 & 2 & 13.89 & 1.91 & 0.09 \\
\hline & & within groups & 591.30 & 57 & 10.55 & & \\
\hline & & Total & 632.98 & 59 & & & \\
\hline & \multirow{3}{*}{$\begin{array}{c}\text { Sleep } \\
\text { disorder } \\
\text { scale }\end{array}$} & Between group & 342.98 & 2 & 48.99 & 8.78 & 0.52 \\
\hline & & within groups & 290 & 57 & 5.57 & & \\
\hline & & Total & 632.98 & 59 & & & \\
\hline Self-trust & sleep & Between group & 63.64 & 2 & 36.58 & 18.56 & 0.76 \\
\hline
\end{tabular}




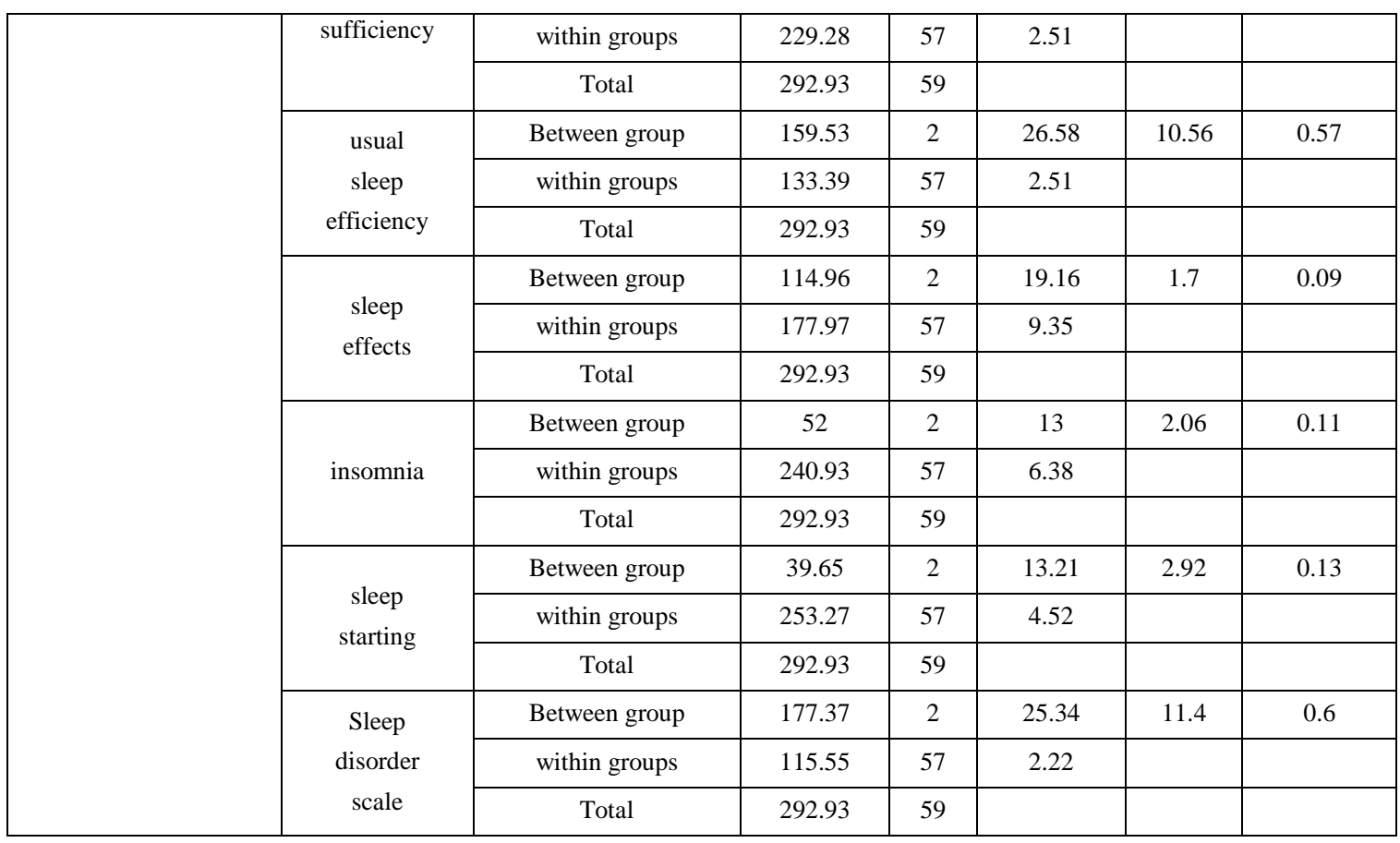

* Significant at $0.05($ F significant $=3.16)$

Table (3) results reveal high effect size for cognitive anxiety on sleep disorder aspects (sleep sufficiency, usual sleep efficiency, sleep starting and sleep disorder scale total) for football players. Largest effect size was in sleep sufficiency. This is consistent with this study results displayed in table (1). Rateb (2007) argues that increases undesired negative thoughts are of cognitive anxiety's distinctive features (p.196).

Table (3) results also reveal no effect for cognitive anxiety on sleep disorder aspects (sleep effects and insomnia) for football players. This is consistent with this study results displayed in table (1). Rateb (2007) argues that somatic anxiety has higher effect than physical performance (p.196).

Table (3) results also reveal high effect size for somatic anxiety on sleep disorder aspects (sleep sufficiency, usual sleep efficiency, insomnia, and sleep disorder scale total) for football players. Largest effect size was in sleep sufficiency (0.75). This is consistent with this study results displayed in table (1). In addition, it is consistent with Juliff, Halson \& Peiffer (2015) conclusions that athletes reported the likelihood of poor sleep increased before competition.

Table (3) results also reveal no effect for somatic anxiety on sleep disorder aspects (sleep effects and sleep starting). This is consistent with this study results displayed in table (1). Rateb (2007) argues that cognitive anxiety has more pronounced effect on athlete's mental processes (p.196).

Table (3) results reveal high effect size for self-trust on sleep disorder aspects (sleep sufficiency and usual sleep efficiency and sleep disorder scale total) for football players. Largest effect size was in sleep sufficiency. This is consistent with this study results displayed in table (1). Fernandez-Fernandez et al (2014) results indicated there great interaction between psychological and physiological responses, evident in real competition, where winning players were much higher in self-trust and lower in cognitive and somatic anxiety than losers.

Table (3) results also reveal no effect for somatic anxiety on sleep disorder aspects (sleep effects, insomnia and sleep starting) for football players. This is consistent with this study results displayed in table (1). Fullagar et al (2014) argues that poor sleep has negative effect on cognitive aspects.

Table (3) results also reveal that self-trust had the highest effect size on sleep disorder scale. Rateb (2000) argues that self-trust is related to the athlete's Selfesteem, it is of most important psychological skills, which should be considered when preparing athletes for competition (p. 300),

Thus, fourth hypothesis partially accepted 
Table (4)

Differences significance in sport anxiety and sleep disorders aspects according to competition levels (premier league $B$ - Third class) $(\mathrm{n} 1=\mathrm{n} 2=30)$

\begin{tabular}{|c|c|c|c|c|c|c|c|}
\hline \multirow{2}{*}{ S.No. Statistics } & \multirow{2}{*}{ Variables } & \multicolumn{2}{|c|}{ premier league B } & \multicolumn{2}{c|}{ Third class } & \multicolumn{2}{c|}{$\begin{array}{c}\text { Mean } \\
\text { differences }\end{array}$} \\
\cline { 2 - 7 } & Mean & SD & Mean & SD & T \\
\hline 1 & Cognitive anxiety & 26.11 & 4.53 & 25.35 & 4.05 & 0.76 & 0.62 \\
\hline 2 & somatic anxiety & 18.46 & 4.47 & 18.48 & 2.04 & -0.02 & -0.01 \\
\hline 3 & Self-trust & 33.82 & 2.33 & 32.52 & 2.56 & 1.29 & $2.09^{*}$ \\
\hline 4 & sleep sufficiency & 11.64 & 2.63 & 11.96 & 2.49 & -0.32 & -0.43 \\
\hline 5 & usual sleep efficiency & 10.04 & 2.32 & 10.65 & 2.21 & -0.61 & -0.8 \\
\hline 6 & sleep effects & 9.21 & 1.59 & 10.69 & 1.18 & -1.48 & $-3.69^{*}$ \\
\hline 7 & insomnia & 9.18 & 1.12 & 10.22 & 0.99 & -1.04 & $-3.45^{*}$ \\
\hline 8 & sleep starting & 8.82 & 0.9 & 9.52 & 1.04 & -0.7 & $-2.57^{*}$ \\
\hline 9 & Sleep disorder scale & 48.89 & 4.41 & 53.04 & 5.99 & -4.15 & $-2.46^{*}$ \\
\hline
\end{tabular}

* Significant at $0.05(\mathrm{~T}$ significant $=\mathbf{2 . 0 0})$

Table (4) results reveal statistically significant differences (2.09) in self-trust aspect according to competition level towards lower level, third class football players. This could attributed to the fact that self-trust increases as competition because of experience, age, high physical and skill level and what player gained from emotional experience through his participation in sports competitions. Table (5) results also reveal insignificant differences in (cognitive anxiety and physical anxiety). This may be because football is team game in which the winning and losing effect distributed among all team members participated in competitive situation. Therefore, there is no significant differences in these two anxiety aspects, like individual games, where sole responsibility of player. This is consistent with Filaire, Sagnol, Ferrand, Maso, \& Lac. (2001) conclusion that individual games' players showed high physical and somatic anxiety and decreased self-trust before competition.

Table (4) results also reveal statistically significant differences in sleep disorder aspects (sleep effects, insomnia and sleep starting) according to competition level towards lower level, third class football players. Largest difference was in sleep effects. Same table also reveal insignificant differences in (sleep sufficiency, usual sleep efficiency) aspects. This because as sports competition level is higher as players are more able to face pressures associated with competition because of their experience. While the effects of sleep disorder (sleep sufficiency, usual sleep efficiency) appear on all players, where competition state is different from normal states that player face in normal life, therefore all players affected equally. This is consistent with Fullagar et al (2014) findings, which stated that the lack of sleep before the competition were due to anxiety, nervousness, and sleep deprivation has negative effect on sport performance. It is also consistent with Mah, Mah, Kezirian, \& Dement (2011) finding that sleep extension, and optimal sleep, is beneficial in reaching athletic peak performance.

\section{Conclusions}

1- The proposed sleep disorder with its five aspects is reliable in measuring sleep disorders within football players.

2- There is a statistically significant correlation between competition anxiety aspects and some sleep disorders aspects within football players.

3- There are statistical differences in the dimensions of the anxiety of competition and the dimensions of sleep disorders between the first measurement (before the competition a month) and the second measurement (before the competition an hour) for football players.

4- Some competition anxiety aspects have effect size $\geq$ 0.14 on some sleep disorders aspects for football players.

5- There are statistically significant differences in some competition anxiety aspects and some disorders aspects for football players according to competition level. 


\section{Recommendations}

1- Using sleep disorders scale to identify sleep state for football players.

2- Attention should be given to good psychological preparation of football players, and athletes to contribute to reduce psychological pressure and achieve maximum possible athletic achievement.

3- Conduct similar research for current study in other sports.

\section{References}

1- American Academy of Sleep Medicine (AASM). (2010, May 27). Getting extra sleep improves the athletic performance of collegiate football players. Retrieved September 10, 2016, from http://www.aasmnet.org/articles.aspx?id=1731

2- Arcos-Carmona, I. M., Castro-Sánchez, A. M., Matarán-Peñarrocha, G. A., Gutiérrez-Rubio, A. B., Ramos-González, E., \& Moreno-Lorenzo, C. (2011). Effects of aerobic exercise program and relaxation techniques on anxiety, quality of sleep, depression, and quality of life in patients with fibromyalgia: a randomized controlled trial. Medicina Clinica, 137(9), 398-401.

3- Fernandez-Fernandez, J., Boullosa, D., SanzRivas, D., Abreu, L., Filaire, E., \& MendezVillanueva, A. (2015). Psychophysiological stress responses during training and competition in young female competitive tennis players. International Journal of Sports Medicine, 36(1), 22-28. doi:10.1055/s-00341384544

4- Filaire, F., Sagnol, M., Ferrand, C., Maso, F., \& Lac, G. (2001). Psychophysiological stress in judo athletes during competitions. J Sports Med Phys Fitness, 41(2), 263-268.

5- Fullagar, H. H., $\quad$ Skorski, S., Duffield, R., Hammes, D., Coutts, A. J., \& Meyer, T. (2014). Sleep and athletic performance: The effects of sleep loss on exercise performance, and physiological and cognitive responses to exercise. Sports Medicine, 45(2), 161-186. doi:10.1007/s40279-014-0260-0

6- Hassan, E. A. (2011). Psychological and educational statistics: applications using SPSS 18. Cairo, Egypt: Dar Al-Fikr Al-Arabi.

7- Ibrahim, H. M. (2008). Sports competition anxiety's physio;ogy. Cairo, Egypt: Dar Al-Wafaa publishing.

8- Juliff, L. E., Halson, S. L., \& Peiffer, J. J. (2015). Understanding sleep disturbance in athletes prior to important competitions. Journal of Science and Medicine in Sport, 18(1), 13-18. doi:10.1016/j.jsams.2014.02.007

9- Mah, C. D., Mah, K. E., Kezirian, E. J., \& Dement, W. C. (2011). The effects of sleep extension on the athletic performance of collegiate basketball players. Sleep, 34(7), 943-950. doi:10.5665/sleep.1132

10- Rateb, O. K. (2004). Psychological skills training: applications in sports field (2nd ed.). Cairo, Egypt: Dar Al-Fikr Al-Arabi.(In Arabic)

11- Rateb, O. K. (2007). Sport psychology: concepts and applications. Cairo, Egypt: Dar Al-Fikr Al-Arabi.

12- Salama, M. A. (2001). Concepts in sports competing psychology. Cairo, Egypt: Mahi publishing and distribution. 